\begin{tabular}{llllllll} 
O P E R A T I O N S R E S E A R C H A N D D E C I S I O N S \\
\hline No. 1
\end{tabular}

DOI: $10.37190 /$ ord210106

\title{
MEASUREMENT OF CONTROL POWER IN CORPORATE NETWORKS
}

\author{
IZABELLA STACH $^{1 *}$, JACEK MERCIK ${ }^{2}$ \\ ${ }^{1}$ AGH University of Science and Technology, al. Mickiewicza 30, 30-059 Kraków, Poland \\ ${ }^{2}$ WSB University in Wroclaw, ul. Fabryczna 29/31, 53-609 Wrocław, Poland
}

\begin{abstract}
This paper discusses some game-theoretical methods for measuring indirect control in complex corporate shareholding networks. The methods use power indices to estimate the direct and indirect control in shareholding structures. Some of these methods only estimate the control power of investors (firms without shareholdings), and only a few measure the control power of all firms involved in shareholding networks (which means investors and stock companies). None of them takes measuring the importance of mutual connections (edges in the networks) into consideration; thus we focus in particular on an extension of these methods in this paper to measure both the control-power of the firms involved in complex shareholding structures (represented by nodes in networks) and the importance (power) of linkages between the firms as elements of a whole corporate shareholding network. More precisely, we apply our approaches to a theoretical example of a corporate network. Moreover, we continue the considerations about reasonable properties for indirect control measurement. Some ideas of new properties are proposed. The paper also provides a brief review of the literature concerning the topic.
\end{abstract}

Keywords: corporate networks, indirect control, simple games, power indices

\section{Introduction}

Research on the power of different shareholders and (particularly) the importance of stakeholder groups for determining voting power was initiated by Berle and Means [4]. The game-theoretical approach to the measurement of the control power of firms in corporate networks dates back to 1994 when the first approach to this issue was proposed by Gambarelli and Owen [20]. Since then, a lot of research has proposed other methods. Among the numerous approaches, let us mention some that used power indices to measure the importance of firms in corporate shareholding networks: Turnovec [45], Hu and Shapley [21, 22], Leech [29], where an empirical analysis of the situation of minority

*Corresponding author, email address: istach@zarz.agh.edu.pl

Received 9 September 2020, accepted 15 March 2021 
shareholders in UK companies is presented, then Crama and Leruth [11, 12], Karos and Peters [25], Mercik and Lobos [33], and Levy and Szafarz [30]. More on the applications and comparisons of some of these methods can be found in $[6,27,34,43]$.

We would like to underline that the Karos and Peters' [25], and Mercik and Lobos' [33] methods provide indices that measure the power of all firms in corporate shareholding networks (which means investors and stock companies). However, neither of these methods nor the others measure the importance of mutual connections (linkages in networks). Thus, we focus in particular on an extension of these methods in this paper to measure both the control-power of firms involved in complex shareholding structures (represented by nodes in networks) and the importance (power) of linkages between the firms as elements of a whole corporate shareholding network. More precisely, we apply our approaches to a theoretical example of a corporate network. Moreover, we continue the considerations [34] about the reasonable properties for indirect control measurement. Some ideas of new properties are undertaken.

The paper is structured as follows. Section 2 introduces the preliminary definitions and notations of cooperative game theory and power indices. In Section 3, we introduce our approach to measure the power of linkages in corporate networks by removing them from the networks; we then apply this method to a theoretical example of a corporate structure. In this scope, we extend the Karos and Peters [25] and Mercik and Lobos [33] indices as well as a modification of Mercik and Lobos (Mercik and Stach [34]) to measure the importance of linkages. In Section 4, we consider some desirable properties of indirect control measure (among these are some that refer to the addition/elimination of links in corporate networks). Finally, Section 5 concludes with some remarks.

\section{Preliminary definitions}

Let $N=\{1,2, \ldots, n\}$ be a finite set of $n$ players. Any subset $S \subseteq N$ is called a coalition. A cooperative $n$-person game $v$ is a function $v: 2^{N} \rightarrow R$, with $v(\varnothing)=0$, defined on the family of all coalitions $2^{N} ; v(S)$ denotes the worth of coalition $S$ in $v$. A cooperative game $v$ is monotonic if $v(S) \leq v(T)$ whenever $S \subset T \subseteq N$. A simple game is a monotonic game $v: 2^{N} \rightarrow\{0,1\}$ such that $v(N)=1$; for all $S \subseteq N$, if $v(S)=1$, coalition $S$ is called a wining coalition; otherwise, a coalition $S$ with $v(S)=0$ is called a losing coalition. A simple game $(N, v)$ is said to be proper if and only if the following requirement is satisfied: for all $T \subseteq N$, if $v(T)=1$, then $v(N \backslash T)=0$. We only analyse the proper simple games where players can vote only yes-no (for more on a proper simple game, see [40], for example). A player $i$ is critical (or a swing player, or decisive) in coalition $S$ if $S$ with $i$ is winning and $S$ without $i$ is losing. A player who is not critical in any coalition (i.e., $v(S \cup\{i\})=v(S)$ for $S \subseteq N \backslash\{i\}$ ) is called a null player, whereas 
player $i$ is called a dummy player in $v$ if $v(S \cup\{i\})-v(S)=v(\{i\})$ for all $S \subseteq N \backslash\{i\}$. If coalition $S$ has at least one critical player, then $S$ is called a vulnerable (or sensitive) coalition. The collection of all vulnerable coalitions is denoted by $V C$, while $V C_{i}$ denotes the set of all vulnerable coalitions that contain player $i$. For each $S \in V C$, the inverse of the number of swing players in $S, r(S)$, is called the fractional swings for the coalition. For instance, if there are only two critical players in a coalition $S \in V C$, then $r(S)=1 / 2$. For each $i \in S \in V C$, we define

$$
r_{i}(S)= \begin{cases}r(S) & \text { if } i \text { is critical in } S \\ 0 & \text { otherwise }\end{cases}
$$

A winning coalition $S$ with all critical players is called a minimal winning coalition. For each player $i$ in $N$, we denote the set of all coalitions in which $i$ is critical by $\eta_{i}=\{S \subseteq N: i \in S \wedge v(S)=1 \wedge v(S \backslash\{i\})=0\}$.

Let $\left(w_{1}, \ldots, w_{n}\right)$ be a non-negative vector of weights of players in $N=\{1, \ldots, n\}$, and let $q$ be a positive real number such that $\sum_{i \in N} w_{i} \geq q>\sum_{i \in N} \frac{w_{i}}{2}$. Then the weighted majority game $\left[q ; w_{1}, \ldots, w_{n}\right]$ is the simple game $(N, v)$ defined as

$$
v(S)= \begin{cases}1 & \text { if } \sum_{i \in S} w_{i} \geq q \\ 0 & \text { otherwise }\end{cases}
$$

The symbol $\left[q ; w_{1}, \ldots, w_{n}\right]$ is used as the representation of a weighted majority game with majority threshold $q$ and weights $w_{1}, \ldots, w_{n}$ that are ordered in a non-increasing sequence. When the weights are the voting rights owned in a stock company in a corporate network, then we can use the concept of a weighted majority game to model the voting situations in this company. Note that, in this paper, voting rights mean voting shares; i.e., shares that give the stockholder the right to vote on corporate matters. Many companies also issue nonvoting shares. There are different classes of shares (e.g., common and preferred shares). All types of shares represent ownership in a company; however, they give different privileges. For example, common shares generally have voting rights, and most common shares give the holder one vote per each share owned (although it does not always work out like this). On the other hand, preferred shares generally do not have voting rights. Some preferred stocks give one vote per share, while others grant more, fewer, or no voting rights at all ${ }^{1}$. This non-linearity often allows control of company operations without holding a qualified majority of shares.

${ }^{1}$ See [23] for example. 


\subsection{Classical power indices}

To measure the voting power of players in a simple game, the concepts of power indices are introduced. Generally, for every simple game $v$, a power index $f$ assigns unique vector $f(v)=\left(f_{1}(v), f_{2}(v), \ldots, f_{n}(v)\right)$, where $f_{i}(v)$ can be interpreted as a measure of the power of player $i$ in simple game $v$. The best-known power index was introduced by Shapley and Shubik [39]. The Shapley-Shubik index for simple game $v$ and each $i \in N$ is given by

$$
\sigma_{i}(v)=\sum_{S \in \eta_{i}} \frac{(s-1) !(n-s) !}{n !}
$$

where $s=|S|$. (Here and hereafter, operator $|\cdot|$ denotes the cardinality of a finite set). For more information of $\sigma$, see [41], for example.

The second best-known and used power index (the Banzhaf index) is proposed by Penrose [37] and Banzhaf [2]. This index is based on the concept of a swing player. Absolute Banzhaf power index $\beta$ for simple game $v$ and each $i \in N$ is defined as follows:

$$
\beta_{i}(v)=\frac{\left|\eta_{i}\right|}{2^{n-1}}
$$

whereas the relative version of the Banzhaf index $\left(\beta^{\prime}\right)$ obtained by normalizing the $\beta$ index so that the indices sum to one is defined as

$$
\beta_{j}^{\prime}(v)=\frac{\left|\eta_{i}\right|}{\sum_{j \in N}\left|\eta_{j}\right|}
$$

More on the Banzhaf indices can also be found in [7, 15], for example.

The Johnston power index ( $J$-power) [24] was introduced for simple game $v$ and each $i \in N$ as follows:

$$
J_{i}(v)=\frac{\sum_{S \in V C} r_{i}(S)}{\sum_{j \in N} \sum_{S \in V C} r_{j}(S)} \text { for each } i \in N
$$


Since the Johnston index is not so frequently applied, we provide a simple example (also considered in [32]) to show the behavior of this index as compared to those commonly used in the Banzhaf and Shapley-Shubik indices. Let us consider the following example: Game $[4 ; 3,2,1]$; i.e., voting where there are three voters, $N=\{1,2,3\}$, each with 3, 2, and 1 votes, respectively. The majority needed for a decision is $q=4$. Coalitions $\{1,2\},\{1,3\}$, and $\{1,2,3\}$ are vulnerable coalitions in this game (vulnerable coalitions must be winning coalitions).

Table 1. Johnston power indices for game [4; 3, 2, 1]. Source: [32]

\begin{tabular}{|c|c|c|c|c|c|c|c|}
\hline \multirow{2}{*}{$\begin{array}{l}\text { Vulnerable } \\
\text { coalitions }\end{array}$} & \multirow{2}{*}{$\begin{array}{c}\text { Number } \\
\text { of vulnerable } \\
\text { coalitions }\end{array}$} & \multicolumn{3}{|c|}{ Critical defections } & \multicolumn{3}{|c|}{ Fractional critical defections } \\
\hline & & $\begin{array}{l}\text { Player } 1 \\
\text { (3 votes) }\end{array}$ & $\begin{array}{l}\text { Player } 2 \\
(2 \text { votes })\end{array}$ & $\begin{array}{l}\text { Player } 3 \\
\text { (1 vote) }\end{array}$ & $\begin{array}{l}\text { Player } 1 \\
\text { (3 votes) }\end{array}$ & $\begin{array}{l}\text { Player } 2 \\
\text { (2 votes) }\end{array}$ & $\begin{array}{l}\text { Player } 3 \\
(1 \text { vote })\end{array}$ \\
\hline$\{1,2\}$ & 1 & 1 & 1 & 0 & $1 / 2$ & $1 / 2$ & 0 \\
\hline$\{1,3\}$ & 1 & 1 & 0 & 1 & $1 / 2$ & 0 & $1 / 2$ \\
\hline$\{1,2,3\}$ & 1 & 1 & 0 & 0 & 1 & 0 & 0 \\
\hline Total & 3 & 3 & 1 & 1 & 2 & $1 / 2$ & $1 / 2$ \\
\hline $\begin{array}{ll}J_{i} \\
\end{array}$ & & & & & $4 / 6$ & $1 / 6$ & $1 / 6$ \\
\hline
\end{tabular}

It is easy to notice that vector $(4 / 6,1 / 6,1 / 6)$ of the $J$-power indices in this example differs from the vector of the relative Banzhaf power indices $(3 / 5,1 / 5,1 / 5)$ and is equal to the vector of Shapley-Shubik power indices $(4 / 6,1 / 6,1 / 6)$. Of course, the three power indices mentioned here are generally different and result from different axiomatic characterisations. For a comparison and axiomatic characterisations of these as well as other indices, see [5], for example.

\subsection{Power indices for measuring power control in corporate networks}

Now, we define three indices introduced for measuring the power control of firms in shareholding structures.

\subsubsection{Karos and Peters approach}

Karos and Peters [25] propose index $\Phi$ to measure the power of all firms in a corporate network. They model the indirect relations among firms using so called invariant mutual structure. Let $N$ be a set of all firms in a corporate shareholding structure. The invariant mutual control structure $C$ is a function which assigns to each coalition $S \in 2^{N}$ the set of all players (firms) controlled by $S$, such that

- $C(\varnothing)=\varnothing$,

- $C(S) \subseteq C(T)$ ) for all $S \subseteq T \subseteq N$ (monotonicity property), 
- $\forall R, S, T \in 2^{N}$ with $S \subseteq C(T)$ and $R \subseteq C(S \cup T)$ we have $R \subseteq C(T)$ (indirect control property).

Let $\bar{C}$ be the set of all invariant mutual control structures based on $N$. For every $C \in \bar{C}$ there is associated a vector of simple games $v^{C}$ (a simple game structure) where each simple game $v_{k}^{C}$ indicates who controls the corresponding firm $k \in N$ for invariant mutual structure $C$, and $v_{k}^{C}(S)=1$ if $k$ is controlled by $S$ (i.e. $k \in C(S)$; otherwise, $v_{k}^{C}(S)=0$. So, for each firm in a corporate shareholding network, there is a (monotonic) simple game whose winning coalitions are exactly those that control that firm. The Karos-Peters index is defined as follows:

$$
\Phi_{i}(C)=\sum_{k \in N} \sigma_{i}\left(v_{k}^{C}\right)-v_{i}^{C}(N) \text { for every } i \in N \text { and } C \in \bar{C}
$$

where $\sigma$ denotes the Shapley-Shubik index, $v_{i}^{C}(N)=0$ for every player $i$ who is never needed by any coalition to exercise its control, and $i$ is also not controlled by any coalition. These kind of players are called by Katos and Peters [25] null players.

\subsubsection{Mercik and Lobos approach}

The method employed by Mercik and Lobos [33] uses an adaptation of the Johnston power index in order to measure indirect control. This index is called the implicit index, and is based on the general assumption that the most commonly used power indices do not adequately describe the situation of "looping" relationships between the shareholders (individual and institutional) of individual companies (see [3, 16, 17, 33] for example). Such "looping" entities and their shareholders are a complementary system existing in a kind of equilibrium in which any change in the volume of shares impacts not only the company itself but the entire system as such.

In implicit index $\pi$, the calculations start with an analysis of the group of companies $C_{1}, \ldots, C_{m}, m \geq 2$. The group of shareholders of $C_{i}$ may include both individual shareholders and other companies.

$$
C_{i}=\left\{s_{k}: k=1,2, \ldots, n_{i}\right\} \cup\left\{c_{j}: j \in\{1, \ldots, m\} \backslash\{i\}\right\}
$$

where $n_{i}$ denotes the cardinality of the group of individual investors ${ }^{2}$ in $C_{i}$. For convenience, if $s_{k}$ and $c_{j}$ represent the share volumes (in percentages) of individual and institutional shareholders represented in $C_{i}$, then

\footnotetext{
${ }^{2}$ By investor we mean a firm that is not controlled by any firm in a corporate shareholding structure.
} 


$$
\sum_{k=1}^{n_{i}} s_{k}+\sum_{j=1}^{m} c_{j}=1
$$

where $s_{k} \geq 0, c_{j} \geq 0$. Using the definition of a winning coalition, coalition $\left\{s_{k}\right\} \cup\left\{c_{j}\right\}$ is a winning coalition if

$$
\sum_{k=1}^{n_{i}} s_{k}+\sum_{\substack{j=1 \\ j \neq i}}^{m} c_{j} \geq q_{i}
$$

where $0.5<q_{i} \leq 1$ is the cumulative volume of shares necessary to make a decision (as we mentioned, only proper games are analysed). Obviously, individual shareholders and institutional investors may be in swing (critical) positions, which makes it possible for coalition $C_{i}$ to be vulnerable. Using sensitive coalitions in $j$ th company $V C_{j}$, one may calculate the absolute value of the Johnston index for each participant in coalition $i \in C_{j}$ as well as for all of the coalition $C_{i}$. After normalisation, the respective values for a participant of the company and for the company in system $C_{1}, C_{2}, \ldots, C_{m}$ is obtained. Then, for each non-individual participant of a coalition $c_{j} \in C_{i}, i=1, \ldots, m$, every value of the power index assigned before $c_{j}$ is divided equally among all shareholders. Subsequently, for each company (members of a system $C_{1}, C_{2}, \ldots, C_{m}$ ) and for each shareholder $c_{j} \in C_{i}$, the absolute value of the implicit power index is calculated by summing up the appropriate values in the entire system. Each of the so-calculated absolute values can be appropriately standardised to receive standardised implicit index $\pi_{i}$ for each firm $i$ in a corporate network.

This index takes values from a range of $[0,1]$; the greater the power of a particular member of several coalitions, the closer the value of such a constructed index will be to 1 . The implicit power index of each shareholder has properties and values analogous to a standard $J$-power index.

\subsubsection{Mercik and Stach approach}

Mercik and Stach [34] propose a modification of the implicit index, calling it a modified implicit index. Let us denote this index by $\pi^{\prime}$ here. The main difference between $\pi$ and $\pi^{\prime}$ lies in the calculation of power for the companies (i.e., non-individual participants of coalitions $c_{j} \in C_{i}, i=1, \ldots, m, m \geq 2$ ). Precisely, the first step in calculating $\pi^{\prime}$ is the same as for the $\pi$ index: after taking into account all of the companies and 
the vulnerable coalitions within these companies, the absolute Johnston index is calculated for all of the companies and investors. In the second step, there is a difference for the companies. For each company, we distribute the amount assigned in the first step to the companies that are among the shareholders of $C_{i}$ proportionally to the absolute Johnston power index distribution given in the first step instead of dividing this amount equally among its shareholders. Then, the third and last step is the same as for index $\pi$, i.e., index $\pi^{\prime}$ is calculated for each firm by summing up the appropriate values in the entire system. After this, the standardisation is made for the companies and investors separately. This modification provides that the $\pi^{\prime}$ index avoids the assignment of positive power to null players, i.e., investors that are not critical in any vulnerable coalition.

\section{Measurement of control power of mutual connections in corporate networks}

In this section, we propose an idea how to evaluate the power of mutual connections (linkages) in corporate shareholding structures. As the edges do not exist separately without the nodes in a network, we propose measuring the power of linkages using the changes in the power of the nodes. More precisely, our proposition is to assign the power equal to the difference of the power values calculated for firm $i$ to a linkage that starts in firm $i$ before and after removing this linkage from the corporate network. In order to assess the value of a linkage, we calculate the pre- and post-elimination distributions of power for the firms (marginal values). We can calculate the distribution of power among the firms in the corporate shareholding structures using the Karos-Peters, Mercik-Lobos, or modified Mercik-Lobos indices (for example).

Some postulates for the good measure of the power (importance) of the linkages in the corporate shareholding network are as follows:

- We assume that the graph is directed. This means that the cross-shareholdings are presents by two connections and not one ${ }^{3}$.

- We would like to have symmetric measurement. This means that we would like a measure that satisfies the symmetry (or anonymity) postulate that states that a linkage's power value should not depend on its name for the arcs in the corporate networks. In other words, let us consider all directed paths in a network to which two linkages belong if the corresponding sets of the directed paths for the two linkages are symmetrical (i.e., paths that have equal linkages with equal voting rights), then the power value

\footnotetext{
${ }^{3}$ The assumption about only one or (maximally) two connections between two nodes in a corporate network can be violated in certain cases, as when we would like introduce other characteristics about the relationships between the firms in corporate networks. Forlicz et al. [18] propose the Shapley value for such multigraphs.
} 
of these two linkages should be equal. Therefore, the "symmetric" linkages should have equal power.

- We would like to have a measure that assigns null power to linkage $(i, j)$ that does not bring changes in power to firm $i$.

If we consider a measure of the firms' indirect control that satisfies the null player property (which states that a null player should obtained nothing) and, as a consequence, the null-player removable property ${ }^{4}$ (like the Karos-Peters or modified Mercik-Lobos methods, for example), then eliminating the linkages that start in the firms that are null players does not change the power of the rest of the firms in the network. So, the importance (power) of these linkages should be null.

Let us provide a formal definition of a measure of the power of linkages in a corporate network that can be seen as an extension of the measures of control power of firms in corporate networks. Let $M(N, L)$ be a corporate network with at least two firms $(|N| \geq 2$ ) and at least one linkage $|L| \geq 1$ ( $N$ denotes a set of all firms, and $L$ is a set of all links in network $M(N, L))$. ) Let $(i, j)$ be a linkage in network $M$, which starts in firm $i$ and finishes in firm $j, i \neq j$. If we remove linkage $(i, j)$ from $M$, we obtain new network $M^{\prime}=M(N, L \backslash(i, j))$. Let $f$ be a power index that assigns the real number interpreted as the power of firm $i$ to each in the entire network $M(N, L)$. The measure of linkage $(i, j)$ is defined as follows:

$$
f_{(i, j)}(M)=f_{i}(M)-f_{i}\left(M^{\prime}\right)
$$

Example 1a. Let us consider a theoretical example of a corporate network used in $[34,43]$ (Fig. 1). We regard a simple majority rule to measure the control power of firms in this example, i.e., $q=(50 \%$ of a company's voting rights +1$)$. The numbers on the links describe the voting rights (in percentages). For example, we have $90 \%$ on link $(7,4)$, which means that firm 7 has $90 \%$ of the voting rights in company 4 .

Example 1b. Let us consider a modified theoretical example of a corporate network used in Example 1a. Namely, we delete the direct link $(7,4)$ designed by a dotted line in Fig. 1. In this way, we get a new network that differs only from that of Example 1a in having one less linkage, i.e., linkage $(7,4)$. As previously, we regard a simple majority rule to measure the control power of firms in this example.

Taking into account the direct and indirect control in Examples 1a (with link $(7,4)$ ) and $1 \mathrm{~b}$ (without link $(7,4)$ ) of the theoretical corporate structure, we find the sets of all

\footnotetext{
${ }^{4}$ The null player removable postulate states that, after eliminating the null players from a game, the non-null players' measures of power remain unchanged (see [14] or [42], for example).
} 
minimal winning coalitions for all companies (Table 2). Then, considering only the direct control in companies $1,2,3,4$, and 5, we find the sets of vulnerable coalitions that are necessary for calculating implicit indices $\pi$ and $\pi^{\prime}$ in both examples (see also Table 2).

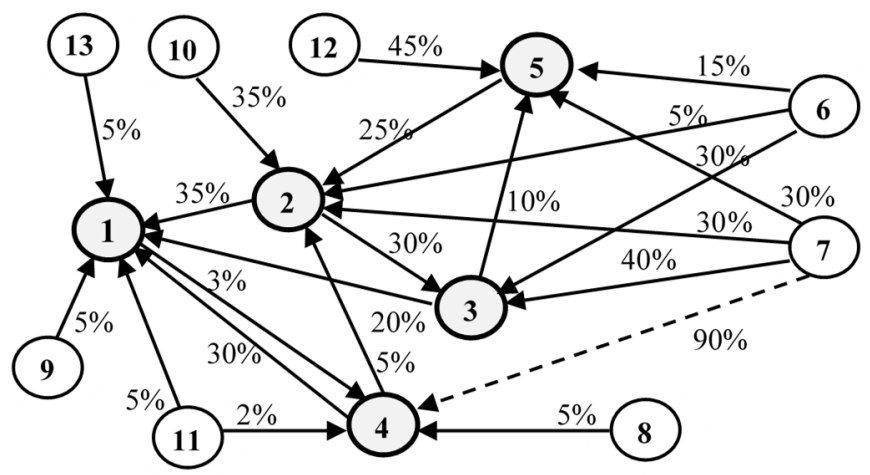

Fig. 1. Corporate shareholding network with 13 firms. Source: [34]

Table 2. Minimal winning and vulnerable coalitions in Examples 1a and 1b

\begin{tabular}{|c|c|c|}
\hline $\begin{array}{l}\text { Company/ } \\
\text { Example }\end{array}$ & $\begin{array}{l}\text { Minimal winning coalitions } \\
\text { considering direct and indirect control }\end{array}$ & $\begin{array}{l}\text { Vulnerable coalitions considering only direct } \\
\text { control. Critical players are underscored }\end{array}$ \\
\hline $1 / 1 \mathrm{a}$ & $\begin{array}{c}\{2,3\},\{2,4\},\{2,6\},\{2,7\},\{3,7,9\} \\
\{3,7,11\},\{3,7,13\},\{5,7\},\{6,7\} \\
\{7,10\},\{7,12\},\{3,10,12\},\{3,5,10\} \\
\{3,4,9\},\{3,4,11\},\{3,4,13\} \\
\{4,5,10\},\{5,6,10\},\{6,10,12\}\end{array}$ & \multirow{2}{*}{$\begin{array}{c}\{\underline{2}, \underline{3}\},\{\underline{2}, \underline{4}\},\{\underline{2}, 3,4\},\{\underline{2}, \underline{3}, 9\}, \\
\{\underline{2}, \underline{3}, 11\},\{\underline{2}, \underline{3}, 13\},\{\underline{2}, \underline{4}, 9\},\{\underline{2}, \underline{4}, 11\}, \\
\{\underline{2}, \underline{4}, 13\},\{\underline{3}, \underline{4}, \underline{9}\},\{\underline{3}, \underline{4}, \underline{11}\},\{\underline{3}, \underline{4}, \underline{13}\}, \\
\{\underline{2}, \underline{3}, 9,11\},\{\underline{2}, \underline{3}, 9,13\},\{\underline{2}, \underline{3}, 11,13\}, \\
\{\underline{2}, \underline{4}, 9,11\},\{\underline{2}, \underline{4}, 9,13\},\{\underline{2}, \underline{4}, 11,13\}, \\
\{\underline{3}, \underline{4}, 9,11\},\{\underline{3}, \underline{4}, 9,13\}, \\
\{\underline{3}, \underline{4}, 11,13\},\{\underline{2}, \underline{3}, 9,11,13\}, \\
\{\underline{2}, \underline{4}, 9,11,13\},\{\underline{3}, \underline{4}, 9,11,13\}\end{array}$} \\
\hline $1 / 1 b$ & $\begin{array}{c}\{2,3\},\{2,4\},\{2,6\},\{2,7\},\{5,7\}, \\
\{6,7\},\{7,10\},\{7,12\},\{3,10,12\} \\
\{3,5,10\},\{3,4,9\},\{3,4,11\},\{3,4,13\} \\
\{4,5,10\},\{5,6,10\},\{6,10,12\}\end{array}$ & \\
\hline $\begin{array}{c}\text { 2/1a } \\
\text { and } 2 / 1 b\end{array}$ & $\begin{array}{l}\{5,7\},\{5,10\},\{6,7\},\{7,10\}, \\
\{7,12\},\{3,10,12\},\{6,10,12\}\end{array}$ & $\begin{array}{c}\{\underline{5}, \underline{7}\},\{\underline{5}, \underline{10}\},\{\underline{7}, \underline{10}\},\{4, \underline{5}, \underline{7}),\{4, \underline{5}, \underline{10}) \\
\{4, \underline{7}, \underline{10}\},\{\underline{5}, 6, \underline{7}\},\{\underline{5}, 6, \underline{10}\},\{6, \underline{7}, \underline{10}\} \\
\{4, \underline{5}, 6, \underline{7}\},\{4, \underline{5}, 6, \underline{10}\},\{4,6, \underline{7}, \underline{0}\}\end{array}$ \\
\hline $\begin{array}{c}3 / 1 \mathrm{a} \text { and } \\
3 / 1 \mathrm{~b}\end{array}$ & $\begin{array}{c}\{2,6\},\{2,7\},\{5,7\},\{6,7\},\{7,10\}, \\
\{7,12\},\{5,6,10\},\{6,10,12\}\end{array}$ & $\{\underline{2}, \underline{6}\},\{\underline{2}, \underline{7}\},\{\underline{6}, \underline{7}\}$ \\
\hline $4 / 1 \mathrm{a}$ & & \multirow{2}{*}{$\begin{array}{c}\{\underline{7}\},\{1, \underline{7}\},\{\underline{7}, 8\},\{\underline{7}, 11\},\{1, \underline{7}, 8\}, \\
\{1, \underline{7}, 11\},\{\underline{7}, 8,11\},\{1, \underline{7}, 8,11\}\end{array}$} \\
\hline $4 / 1 b$ & $\{7\}$ & \\
\hline $\begin{array}{c}5 / 1 \mathrm{a} \\
\text { and } 5 / 1 \mathrm{~b}\end{array}$ & $\{3,12\},\{6,12\},\{6,7\},\{7,12\}$ & $\begin{array}{c}\{\underline{3}, \underline{12}\},\{\underline{6}, \underline{12}\},\{\underline{7}, \underline{12}\},\{\underline{3}, \underline{6}, \underline{7}\} \\
\{3,6, \underline{12}\},\{3,7, \underline{12}\},\{6,7, \underline{12}\}\end{array}$ \\
\hline
\end{tabular}

The sets of minimal winning coalitions in Example $1 \mathrm{~b}$ are a bit different from those in Example 1a (with linkage $(7,4)$ ). The differences in sets of minimal winning coalitions are noted for companies 1 and 4 . Precisely, coalitions $\{3,7,9\},\{3,7,11\}$, and $\{3$, 
$7,13\}$ become losing in the game that refers to company 1 , and coalition $\{7\}$ becomes losing in the game that refers to company 4 (Table 2). For the rest of the companies (i.e., companies 2,3 , and 5), the sets of minimal winning coalitions remain the same as in the network with link $(7,4)$.

Table 3. Absolute and standardised values of implicit power index $\pi$ in Example 1a

\begin{tabular}{|c|c|c|c|c|c|c|c|}
\hline \multirow{2}{*}{ Investor } & \multicolumn{5}{|c|}{ Company } & \multirow{2}{*}{$\begin{array}{l}\text { Absolute index } \\
\text { of investor }\end{array}$} & \multirow{2}{*}{$\begin{array}{l}\text { Standardised } \\
\text { index } \\
\text { of investor }\end{array}$} \\
\hline & 1 & 2 & 3 & 4 & 5 & & \\
\hline 6 & 4.1333 & 1.0000 & 1.2000 & & 1.1111 & 7.4444 & 0.1668 \\
\hline 7 & 5.8833 & 5.0000 & 1.2000 & 8.0000 & 1.1111 & 21.1944 & 0.4748 \\
\hline 8 & 1.7500 & & & & & 1.7500 & 0.0392 \\
\hline 9 & 0.3333 & & & & & 0.3333 & 0.0075 \\
\hline 10 & 1.8000 & 4.0000 & 0.2000 & & & 6.0000 & 0.1344 \\
\hline 11 & 2.0833 & & & & & 2.0833 & 0.0467 \\
\hline 12 & & 1.0000 & & & 4.5000 & 5.5000 & 0.1232 \\
\hline 13 & 0.3333 & & & & & 0.3333 & 0.0075 \\
\hline $\begin{array}{l}\text { Absolute index } \\
\text { of company }\end{array}$ & 16.3167 & 11.0000 & 2.6000 & 8.0000 & 6.7222 & $1607 / 36$ & \\
\hline $\begin{array}{l}\text { Standardised index } \\
\text { of company }\end{array}$ & 0.3655 & 0.2464 & 0.0582 & 0.1792 & 0.1506 & & \\
\hline
\end{tabular}

Table 4. Calculations of $\Phi$ index in Example 1a

\begin{tabular}{|c|c|c|c|c|c|c|c|c|}
\hline \multirow{2}{*}{ Firm } & \multicolumn{6}{|c|}{ Power distribution in accordance with $\sigma$ index in a simple game $v_{i}$} \\
\cline { 2 - 10 } & $i=1$ & $i=2$ & $i=3$ & $i=4$ & $i=5$ & $i=6-13$ & Total & $\Phi$ \\
\hline 1 & 0.000 & 0.000 & 0.000 & 0.000 & 0.000 & 0.000 & 0.000 & -1.000 \\
\hline 2 & 0.196 & 0.000 & 0.133 & 0.000 & 0.000 & 0.000 & 0.329 & -0.671 \\
\hline 3 & 0.121 & 0.017 & 0.000 & 0.000 & 0.083 & 0.000 & 0.221 & -0.779 \\
\hline 4 & 0.098 & 0.000 & 0.000 & 0.000 & 0.000 & 0.000 & 0.098 & 0.902 \\
\hline 5 & 0.056 & 0.150 & 0.050 & 0.000 & 0.000 & 0.000 & 0.256 & -0.744 \\
\hline 6 & 0.096 & 0.067 & 0.250 & 0.000 & 0.250 & 0.000 & 0.662 & 0.662 \\
\hline 7 & 0.265 & 0.400 & 0.433 & 1.000 & 0.250 & 0.000 & 2.348 & 2.348 \\
\hline 8 & 0.000 & 0.000 & 0.000 & 0.000 & 0.000 & 0.000 & 0.000 & 0.000 \\
\hline 9 & 0.010 & 0.000 & 0.000 & 0.000 & 0.000 & 0.000 & 0.010 & 0.010 \\
\hline 10 & 0.092 & 0.267 & 0.083 & 0.000 & 0.000 & 0.000 & 0.442 & 0.442 \\
\hline 11 & 0.010 & 0.000 & 0.000 & 0.000 & 0.000 & 0.000 & 0.010 & 0.010 \\
\hline 12 & 0.047 & 0.100 & 0.050 & 0.000 & 0.417 & 0.000 & 0.613 & 0.613 \\
\hline 13 & 0.010 & 0.000 & 0.000 & 0.000 & 0.000 & 0.000 & 0.010 & 0.010 \\
\hline
\end{tabular}

Now, let us calculate the power of linkage $(7,4)$. For this purpose, we have to calculate the power of firm 7 in the whole corporate network pre- and post-elimination of link $(7,4)$, i.e., in Examples 1a and 1b. Of course, elimination of linkage $(i, j)$ from the network changes the network, including decreasing total number of voting rights in 
company $i$. However, we assume that the sum of the shares in each company node is not necessarily equal to $100 \%$. This means that some shares can be dispersed in an ocean of small shareholders. In Tables 3 and 4, we calculate the power of all firms in Example 1a, i.e., in the example of a corporate network with linkage $(7,4)$ using the Mercik-Lobos and the Karos-Peters approaches, respectively. For this purpose, the sets of minimal winning coalitions for all companies $(1,2,3,4,5)$ that take direct and indirect control into account and the sets of vulnerable coalitions that consider only direct control are shown in Table 2.

Namely, the standardised implicit index of thirteen firms in Example 1a is $(0.3655$, $0.2464,0.0582,0.1792,0.1506,0.1668,0.4748,0.0392,0.0075,0.1344,0.0467$, $0.1232,0.0075)$, while the $\Phi$ index is equal to $(-1,-0.671,-0.779,-0.902,-0.744$, $0.662,2.348,0,0.01,0.442,0.01,0.613,0.01)$, see Tables 3 and 4 .

Now, let us consider Example 1b. The elimination of linkage $(7,4)$ changes the sets of minimal-winning coalitions for companies 1 and 4 (as mentioned above). Precisely, coalitions $\{3,7,9\},\{3,7,11\}$, and $\{3,7,13\}$ become losing in the game that refers to company 1 , and coalition $\{7\}$ becomes losing in the game that refers to company 4 (Table 2). For the rest of the companies (i.e., companies 2, 3, and 5), the sets of minimal winning coalitions remain the same as in the network with link $(7,4)$. More precisely, company 4 is not controlled anymore. Regarding company 1, three minimal winning coalitions (i.e., coalitions $\{3,7,9\},\{3,7,11\}$, and $\{3,7,13\}$ ) become losing coalitions. Thus, if we take the Karos-Peters index into consideration to calculate the power of the firms in our example, the elimination of linkage $(7,4)$ mostly influences a change in the power of firms 3 and 7, as these firms belongs to all of the three minimal-winning coalitions mentioned above. Subsequently, the power of firms 9, 11, and 13 will also change.

Table 5. Calculations of $\Phi$ index in Example 1b

\begin{tabular}{|c|c|c|c|c|c|c|c|c|}
\hline \multirow{2}{*}{ Firm } & \multicolumn{6}{|c|}{ Power distribution in accordance with $\sigma$ index in a simple game $v_{i}$} \\
\cline { 2 - 10 } & $i=1$ & $i=2$ & $i=3$ & $i=4$ & $i=5$ & $i=6-13$ & Total & $\Phi$ \\
\hline 1 & 0.000 & 0.000 & 0.000 & 0.000 & 0.000 & 0.000 & 0.000 & -1.000 \\
\hline 2 & 0.200 & 0.000 & 0.133 & 0.000 & 0.000 & 0.000 & 0.333 & -0.667 \\
\hline 3 & 0.112 & 0.017 & 0.000 & 0.000 & 0.083 & 0.000 & 0.212 & -0.788 \\
\hline 4 & 0.102 & 0.000 & 0.000 & 0.000 & 0.000 & 0.000 & 0.102 & 0.102 \\
\hline 5 & 0.060 & 0.150 & 0.050 & 0.000 & 0.000 & 0.000 & 0.26 & -0.74 \\
\hline 6 & 0.100 & 0.067 & 0.250 & 0.000 & 0.250 & 0.000 & 0.667 & 0.667 \\
\hline 7 & 0.256 & 0.400 & 0.433 & 0.000 & 0.250 & 0.000 & 1.339 & 1.339 \\
\hline 8 & 0.000 & 0.000 & 0.000 & 0.000 & 0.000 & 0.000 & 0.000 & 0.000 \\
\hline 9 & 0.008 & 0.000 & 0.000 & 0.000 & 0.000 & 0.000 & 0.008 & 0.008 \\
\hline 10 & 0.096 & 0.267 & 0.083 & 0.000 & 0.000 & 0.000 & 0.446 & 0.446 \\
\hline 11 & 0.008 & 0.000 & 0.000 & 0.000 & 0.000 & 0.000 & 0.008 & 0.008 \\
\hline 12 & 0.051 & 0.100 & 0.050 & 0.000 & 0.417 & 0.000 & 0.618 & 0.618 \\
\hline 13 & 0.008 & 0.000 & 0.000 & 0.000 & 0.000 & 0.000 & 0.008 & 0.008 \\
\hline
\end{tabular}


Note that company 4 is not controlled by any firm in the network in Example 1b; therefore, it is not controlled by set of all firms $(N)$ either. Thus, using the definition of index $\Phi_{i}$, we have $v_{4}(N)=0$. All other companies (i.e., companies 1, 2, 3, and 5) are controlled by $N$, so $v_{i}(N)=1$ for $i=1,2,3,5$. Then, firms $6,7,8,9,10,11,12$, and 13 are not controlled by any firm by definition, as they are investors. Thus, we have $v_{i}(S)=0$ for each $S \subseteq N$ and each $i=6,7,8,9,10,11,12,13$. Table 5 shows the calculations of the $\Phi$ index in our example with link $(7,4)$ eliminated (Example 1b).

The last column in Table 5 gives the $\Phi$ index for all firms; thus, we can see that the power of firm 7 decreased after the elimination of link $(7,4)$. In Example 1b, we find the power of firm 7 is equal to 1.339 , according to the Karos-Peters index. In the original network (with link $(7,4)$ ), the power of firm 7 was 2.348, (Tables 4 and 5). Thus, following our idea and the Karos-Peters index, the power of linkage $(7,4)$ may be estimated as follows:

$$
\Phi_{(7,4)}(M)=\Phi_{7}(M)-\Phi_{7}\left(M^{\prime}\right)=(2.348-1.339)=1.009
$$

where $M^{\prime}$ denotes the corporate network in Example 1b, whereas $M$ denotes the network with link $(7,4)$ added. The power of linkage $(7,4)$ calculated in this way $\left(\Phi_{(7,4)}(M)=1.009\right)$ is an absolute value. After the calculations of power made for all linkages, we can standardise these values.

Table 6. Absolute and standardised values of implicit power index $\pi$ in Example $1 \mathrm{~b}$

\begin{tabular}{|c|c|c|c|c|c|c|c|}
\hline \multirow{2}{*}{ Investor } & \multicolumn{5}{|c|}{ Company } & \multirow{2}{*}{$\begin{array}{l}\text { Absolute index } \\
\text { of investor }\end{array}$} & \multirow{2}{*}{$\begin{array}{c}\text { Standardised index } \\
\text { of investor }\end{array}$} \\
\hline & 1 & 2 & 3 & 4 & 5 & & \\
\hline 6 & 4.1333 & 1.0000 & 1.2000 & & 1.1111 & 7.4444 & 0.2032 \\
\hline 7 & 5.8833 & 5.0000 & 1.2000 & & 1.1111 & 13.1944 & 0.3601 \\
\hline 8 & 1.7500 & & & & & 1.7500 & 0.0478 \\
\hline 9 & 0.3333 & & & & & 0.3333 & 0.0091 \\
\hline 10 & 1.8000 & 4.0000 & 0.2000 & & & 6.0000 & 0.1638 \\
\hline 11 & 2.0833 & & & & & 2.0833 & 0.0569 \\
\hline 12 & & 1.0000 & & & 4.5000 & 5.5000 & 0.1501 \\
\hline 13 & 0.3333 & & & & & 0.3333 & 0.0091 \\
\hline $\begin{array}{l}\text { Absolute index } \\
\text { of company }\end{array}$ & 16.3167 & 11.0000 & 2.6000 & 0 & 6.7222 & $1319 / 36$ & \\
\hline $\begin{array}{l}\text { Standardised index } \\
\text { of company }\end{array}$ & 0.4453 & 0.3000 & 0.0710 & 0 & 0.1835 & & \\
\hline
\end{tabular}

Now, we assess the value of linkage $(7,4)$, applying the Mercik and Lobos $\pi$ index. The elimination of linkage $(7,4)$ does not change the sets of vulnerable coalitions for all companies except for company 4 . In network $M$ (with linkage $(7,4)$, Example 1a), 
firm 7 is critical in the following eight vulnerable coalitions: $\{7\},\{1,7\},\{7,8\},\{7,11\}$, $\{1,7,8\},\{1,7,11\},\{7,8,11\}$, and $\{1,7,8,11\}$ (Table 2), which become losing coalitions in company 4 after the elimination of linkage $(7,4)$. In Table 6 , we provide the calculations of index $\pi$ in Example 1b, i.e., in network $M^{\prime}=M(N, L \backslash\{7,4\})$.

The power control of Investor 7 pre-elimination of link $(7,4)$ is equal to 0.4748 (Table 3); after elimination, this is equal to 0.3601 (Table 6). Hence, the power of linkage $(7,4)$ in whole network is as follows (according to our approach and the Mercik -Lobos index):

$$
\pi_{(7,4)}(M)=\pi_{7}(M)-\pi_{7}\left(M^{\prime}\right)=0.4748-0.3601=0.1147
$$

Now, let us assess the importance of link $(7,4)$, using modified implicit index $\pi^{\prime}$. Table 7 shows all calculations of $\pi^{\prime}$ in Example 1a, i.e., for the network presented in Fig, 1 with linkage $(7,4)$, which indicates that firm 7 holds $90 \%$ of the voting rights in firm 4.

Table 7. Absolute and standardised values of $\pi^{\prime}$ in Example 1a (network with linkage $(7,4)$ )

\begin{tabular}{|c|c|c|c|c|c|c|c|}
\hline \multirow{2}{*}{ Investor } & \multicolumn{5}{|c|}{ Company } & \multirow{2}{*}{$\begin{array}{l}\text { Absolute index } \\
\text { of investor }\end{array}$} & \multirow{2}{*}{$\begin{array}{c}\text { Standardised index } \\
\text { of investor }\end{array}$} \\
\hline & 1 & 2 & 3 & 4 & 5 & & \\
\hline 6 & 2.3333 & 0.4762 & 1 & & 1.11111 & 4.9206 & 0.0999 \\
\hline 7 & 12.3333 & 4.4762 & 1.33333 & 8.0000 & 1.11111 & 27.2540 & 0.5591 \\
\hline 8 & & & & & & 0.0000 & 0.0000 \\
\hline 9 & 0.3333 & & & & & 0.3333 & 0.0069 \\
\hline 10 & 3.0000 & 4.0000 & 0.33333 & & & 7.3333 & 0.1508 \\
\hline 11 & 0.3333 & & & & & 0.3333 & 0.0069 \\
\hline 12 & & 2.5714 & & & 4.5000 & 7.0714 & 0.1696 \\
\hline 13 & 0.3333 & & & & & 0.3333 & 0.0069 \\
\hline $\begin{array}{l}\text { Absolute } \\
\text { index } \\
\text { of company }\end{array}$ & 18.6667 & 11.5238 & 2.6667 & 8.0000 & 6.7222 & 47.5794 & \\
\hline $\begin{array}{l}\text { Standardised } \\
\text { index } \\
\text { of company }\end{array}$ & 0.3923 & 0.2422 & 0.0560 & 0.1681 & 0.1413 & & \\
\hline
\end{tabular}

Table 8 provides the calculations of the $\pi^{\prime}$ index in Example 1b, where link $(7,4)$ is not present.

Based on the calculations of index $\pi^{\prime}$ in Tables 7 and 8 , we can assess the power of linkage $(7,4)$ in the whole network. Namely, the power of linkage $(7,4)$ is as follows (according to our approach and modified index $\pi^{\prime}$ ):

$$
\pi_{(7,4)}^{\prime}(M)=\pi_{7}^{\prime}(M)-\pi_{7}^{\prime}\left(M^{\prime}\right)=0.5591-0.4865=0.0726
$$


Table 8. Absolute and standardised values of $\pi^{\prime}$ in Example $1 \mathrm{~b}$ (network without link $(7,4)$ )

\begin{tabular}{|c|c|c|c|c|c|c|c|}
\hline \multirow{2}{*}{ Investor } & \multicolumn{5}{|c|}{ Company } & Absolute index \\
& \cline { 2 - 7 } & 1 & 2 & 3 & 4 & 5 & $\begin{array}{c}\text { Standardised index } \\
\text { of investor }\end{array}$ \\
\hline 6 & 2.3333 & 0.4762 & 1 & & 1.11111 & 4.9206 & 0.1243 \\
\hline 7 & 12.3333 & 4.4762 & 1.33333 & & 1.11111 & 19.2540 & 0.4865 \\
\hline 8 & & & & & & 0.0000 & 0.0000 \\
\hline 9 & 0.3333 & & & & & 0.3333 & 0.0084 \\
\hline 10 & 3.0000 & 4.0000 & 0.33333 & & & 7.3333 & 0.1853 \\
\hline 11 & 0.3333 & & & & & 0.3333 & 0.0084 \\
\hline 12 & & 2.5714 & & & 4.5000 & 7.0714 & 0.1787 \\
\hline 13 & 0.3333 & & & & & 0.3333 & 0.0084 \\
\hline $\begin{array}{l}\text { Absolute } \\
\text { index } \\
\text { of company }\end{array}$ & 18.6667 & 11.5238 & 2.6667 & 0.0000 & 6.7222 & $4987 / 126$ & \\
\hline $\begin{array}{l}\text { Standardised } \\
\text { index } \\
\text { of company }\end{array}$ & 0.4716 & 0.2912 & 0.0674 & 0.0000 & 0.1698 & & \\
\hline
\end{tabular}

Hence, the $\pi^{\prime}$ index assesses the importance of linkage $(7,4)$ being lower in power than the very similar power index $\pi$; even $\pi^{\prime}$ estimates the power of firm 7 to be greater than $\pi$ in both cases of the corporate network with and without linkage $(7,4)$. Of course, a more adequate way to compare the results would be to use standardised values of the powers of the linkages.

Since firm 8 is a null player in the weighted game that refers to company 4 , it is not difficult to assess the power of linkage $(8,4)$. The elimination of linkage $(8,4)$ from the network regarded in our example (network $M$ with linkage $(7,4)$ ) changes neither the set of minimal winning coalitions nor the sets of vulnerable coalitions for all companies. So, the power of link $(8,4)$ should be null, according to our approach as well as the $\Phi$ and $\pi^{\prime}$ indices.

$$
\Phi_{(8,4)}(M)=\Phi_{8}(M)-\Phi_{8}\left(M^{\prime}\right)=\pi_{(8,4)}^{\prime}(M)=\pi_{8}^{\prime}(M)-\pi_{8}^{\prime}\left(M^{\prime}\right)=0-0=0
$$

Regarding implicit index $\pi$, the power of linkage $(8,4)$ is not null. Firm 8 (being an investor in company 4 , which, in turn, is a shareholder of companies 1 and 2) is an indirect shareholder of companies 1 and 2 . According to the $\pi$ index, the amounts assigned to company 4 are equally divided among its shareholders during its partial calculations for all firms. Therefore, this implies that firm 8 has non-null power in $M$ due to the $\pi$ index; see Table 3 . The elimination of linkage $(8,4)$ from network $M$ implies that firm 8 becomes an isolated node in network $M^{\prime}=M(N, L \backslash\{8,4\})$ with null power. Thus, the power of linkage $(8,4)$ in network $M(N, L)$ is positive and equals the following: 


$$
\pi_{(8,4)}(M)=\pi_{8}(M)-\pi_{8}\left(M^{\prime}\right)=0.0392-0=0.0392
$$

The measure of the linkages in the corporate shareholding structures proposed in this way (i.e., as the extension of firm control power measure $f$ ) should maintain the majority of the characteristics of power index $f$.

\section{On reasonable properties for indirect control measure}

Many scholars focused their attention on the desirable properties of power indices in different contexts, including Bertini et al. [5], Bertini and Stach [8], Stach [42], ÁlvarezMozos et al. [1], Freixas et al. [19], Felsenthal and Machover [17], and Laruelle [28], for example. One of the interesting questions about the measurement of the indirect control of firms and mutual connections in a whole corporate network structure is this: which properties should be met by a good measure (power index) in the context of indirect control.

As mentioned in Section 1, there are various approaches to measure the indirect control power of firms. We particularly concentrate on the approaches proposed by Karos and Peters in [25] (the $\Phi$ index), Mercik and Lobos in [33] (the implicit $\pi$ index), and the modification of the latter (implicit index $\pi^{\prime}$ ) proposed by Mercik and Stach [34]; these are formally described in Section 2. All of these approaches measure the control power of each firm (investors as well as companies) in a whole corporate network. There is also another approach by Levy and Szafarz [30], which considers the power of all firms. However, the last approach calculates the power of each firm in a target company (for all targeted possible companies in a network) and not in the whole corporate shareholding structure.

Among various methods of measuring the indirect control power of firms in corporate networks, only the approach by Karos and Peters [25] starts from a group of properties and arrived at one index. Namely, they regard the anonymity, null player, transfer, constant-sum, and control player properties. As modifications of the Johnston power index [24], the implicit power indices $\left(\pi\right.$ and $\pi^{\prime}$ ) have properties and values that are analogous to the standard $J$-power index. Let us remember some properties that are satisfied by the $J$-power index: dominance, efficiency, null player, non-negativity, and symmetry properties (see [5], for example). Taking into account the procedure of calculating the $\pi$ index, we deduce that $\pi$ does not satisfy the null player property (this could be seen in Examples 1a and 1b for example (Section 3). For this reason, a modification of the Mercik-Lobos index was proposed to satisfy the null player property (the $\pi^{\prime}$ index) in [34]. Still, a more in-depth comparison of these two indices $\left(\pi\right.$ and $\left.\pi^{\prime}\right)$ was made in [34]. 
Mercik and Stach [34] review some available properties of the power indices and reformulate some of them in the context of indirect control. Among the standard properties of the power indices are symmetry, null player, efficiency, and non-negativity properties. The bloc, dominance, donation, and null player removable properties also seem inescapable in an indirect control context. In [34], we propose some formulations of the last five properties mentioned. Here, we would like to revise these formulations and try to improve them as related to measuring the control power of firms both "inside" a company and in a relationship with the "surroundings". In this paper, we regard only the indices that measure the importance of all nodes (firms) in the corporate networks; namely, the $\Phi, \pi$, and $\pi^{\prime}$ indices. All that is new that we know about these power indices and five properties are reported below.

Bloc property. If two firms merge, then the new firm should not have less control power than each of the previous firms. This means that the power of the new firm (also in the new corporate network, which changed due to the merger) is greater than or equal to the maximum power of these two firms in the original network. Let us consider this property inside a company. This means that a merger between firms is realised only between the direct investors of the companies that are not stock companies. Then, the Karos-Peters index should satisfy this property, as the Shapley-Shubik index satisfies the bloc property in weighted majority games (see [5], for example). However, concerning the $\pi$ and $\pi^{\prime}$ indices, these do not satisfy the bloc property, as the $J$-index does not fulfil this property in weighted majority games (see [5], for example).

Dominance property. Let us consider a corporate network in which two firms are almost in the same position. This means they are controlled by the same firms with the same numbers of voting rights (if any) and have the same number of voting rights in the same companies except one, where one of the considered firms has more voting rights than the other. Then, a firm with a larger block of voting rights cannot receive less control power in the whole network than a firm with a smaller block of voting rights. When we regard this property inside a company and for shareholders of the same category (both investors or both companies), all of the indices considered here (namely, $\Phi, \pi$, and $\pi^{\prime}$ ) should satisfy this property, as the Shapley-Shubik and Johnston indices satisfy it in weighted majority games.

Donation property. In a corporate structure, a firm that donates its voting rights to another firm should not increase its control power. If the donation property concerns only the relationships within a company (a transfer of shares between the investors of the same company), the changes in the weights of the players (firms) concern only a weighted majority game associated with this company. The Shapley-Shubik index fulfils the donation property in weighted majority games (see [5], for example); thus, the $\Phi$ index should also fulfil it. An investor donating a part (or all) of its voting rights 
does not increase its control power according to the $\sigma$ index in this company. Then, as its voting rights in other companies do not change, its power in other companies cannot increase; as a consequence, it should not increase the control power in the entire system. The Johnston index does not fulfil the donation property in weighted majority games (see [5], for example). So, in theory, an investor may increase its control power by transferring a part of its voting rights to another investor; as a result, having the same amount of voting rights in other companies effectively increases its control power in the entire network. Hence, the $\pi$ and $\pi^{\prime}$ indices (which are the modification of the $J$-index) do not satisfy this property.

Null player removable property. The null player removable property states that, after removing the null firms (i.e., those firms whose voting rights cannot transform any losing coalition into a winning one), the non-null firms' measures of control power should remain unchanged. The $\pi$ index does not satisfy this property, as can be seen in Examples 1a and $1 \mathrm{~b}$ (where the null player (firm 8) receives non-null power). Still, in [34], we propose a modification of the Mercik-Lobos index (denoted here by $\pi^{\prime}$ ) to satisfy the null player property. Thus, the Karos-Peters $\Phi$ (which satisfies the null player property) and modified implicit $\pi^{\prime}$ indices satisfy this property.

We propose new properties for indirect measures for both contexts: inside a company, and outside as related to a whole network.

The quarrelling property. A firm involved in a quarrel should not increase its power. This property refers to situations when two quarrelling firms do not agree on a particular vote, for example; as a result, they will not cooperate and, consequently, will not form a coalition (and they also cannot take part in any coalition together). Thus, their coalition ability decreases; as a consequence, their power in an entire corporate network should not increase.

For the first time, the quarrelling property (for power indices and simple games) was formulated by Kilgour [26]; it was then studied and discussed by other scholars, such as Brams [10], Nevison [36], Deegan and Packel [13], Straffin [44], and Felsenthal and Machover [16]. The Shapley-Shubik and Banzhaf indices do not fulfil this property in simple games (see [10] for example). In the context of indirect control and corporate networks, this property requires new definitions of power indices in a quarrelling game. So, the issue of satisfying this property in both cases (inside a company and in a whole network) by regarding indices remains an open problem at the moment.

The fairness property. The effect of the link addition was introduced in communication graph games by Myerson [35], who proposed the axiom of fairness. This, along with so-called component efficiency, characterises the Myerson value [35]. This property states that deleting an undirected communication link between two players should 
have the same effect on their respective payoffs. Using the terminology of indirect control in corporate networks, this property could mean that deleting cross-holding between two firms should have the same effect on their control power (of course, only if the voting rights assigned to the two related directed links are the same).

Example 2. Let us consider a corporate shareholding network presented in Fig. 2a. Deleting a cross-holding between companies 3 and 4, we obtain the network in Fig. 2 b. In this example of two shareholdings networks, we can observe a violation of the fairness property by considered indices for measuring power control in corporate networks in this paper.

a)

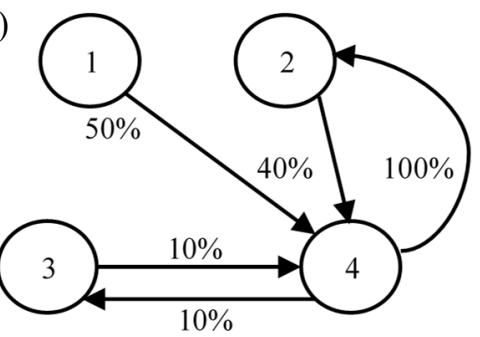

b)

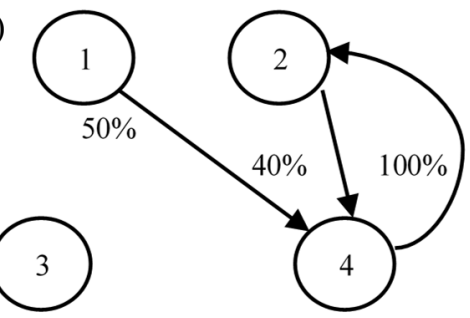

Fig. 2. Corporate shareholding network (a) and the same network with deleted cross-holding between companies 3 and 4 (b)

Namely, comparing the powers assigned by the three indices $\left(\Phi, \pi\right.$, and $\left.\pi^{\prime}\right)$ to firms 3 and 4 in Table 9, we can see that all indices fail the fairness property.

Table 9. Distributions of power for networks shown in Fig. 2

\begin{tabular}{|c|c|c|c|c|c|}
\hline \multirow{2}{*}{ Network } & \multirow{2}{*}{ Index } & Investor & \multicolumn{3}{|c|}{ Company } \\
\cline { 3 - 6 } & & 1 & 2 & 3 & 4 \\
\hline \multirow{4}{*}{ Fig. 2a } & $\Phi_{i}$ & 1 & $-5 / 6$ & $1 / 6$ & $-2 / 6$ \\
\cline { 2 - 6 } & $\pi_{i}$ & 1 & $1 / 7$ & 0 & $6 / 7$ \\
\cline { 2 - 6 } & $\pi_{i}^{\prime}$ & 1 & $1 / 4$ & 0 & $3 / 4$ \\
\hline \multirow{2}{*}{ Fig. 2b } & $\Phi_{i}$ & $5 / 6$ & $-4 / 6$ & 0 & $-1 / 6$ \\
\cline { 2 - 6 } & $\pi_{i}, \pi_{i}^{\prime}$ & 1 & $1 / 2$ & 0 & $1 / 2$ \\
\hline
\end{tabular}

Reviewing the literature on the topic, we find three other properties that refer to the measuring control power of player and link additions in corporate networks. Namely, Peters et al. [38] consider the following three properties of power indices in invariant digraphs. A direct graph (digraph) is called invariant if there is a linkage between any two nodes between which a directed path also exists. 
Link addition 1 property. If player $j$ becomes additionally controlled by some player $i$, then this should not change the power of the players who were already controlling $j$. According to Peters et al. [38], this property is satisfied by multiples of the Copeland score; i.e., a one-parameter family of power indices of the following form: $c$ (the power of player $i$ is equal to the number of players controlled by player $i$ minus the number of players controlling player $i$ ), where $c$ is a real number.

Link addition 2 property. If player $j$ becomes additionally controlled by some player $i$, then this should not change the power of player $j$. This property is satisfied by multiples of the $\beta$-measure $[47,48]$.

Link addition 3 property. This axiom states that, if we add a link from player $i$ to player $j$, then both should have the same gain or loss in power. This property is satisfied by multiples of the apex-measure [46].

The $\Phi, \pi$, and $\pi^{\prime}$ indices fail these three link addition properties presented above in this very general form. These can be demonstrated in simple examples of corporate networks (see Examples 3, 4 and Figs. 3, 4).

a)

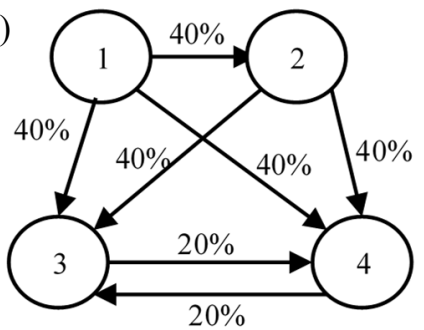

b)

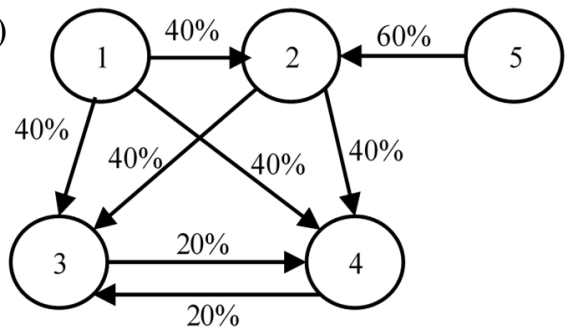

Fig. 3. Network of a simple corporate shareholding structure composed of four firms: three companies (firms 2, 3, and 4), and one investor (firm 1) (a), the same network modified by adding a linkage and one firm (b)

Example 3. Figure 3a shows the network of a simple corporate shareholding structure composed of four firms: three companies (firms 2, 3, and 4), and one investor (firm 1). For this case, the $\Phi, \pi$, and $\pi^{\prime}$ indices are calculated in Table 10 . The network presented in Fig. $3 \mathrm{~b}$ is a modification of the network given in Figure 3a by adding a linkage and one firm (firm 5). In this way, we obtain a new structure composed of three companies (firms 2, 3, and 4) and two investors (firms 1 and 5). For the network given in Fig. 3b, the $\Phi, \pi$, and $\pi^{\prime}$ indices are calculated in Table 11 .

Table 10. Distributions of power for a network shown in Fig. 3a

\begin{tabular}{|c|c|c|c|c|}
\hline \multirow{2}{*}{ Index } & Investor & \multicolumn{3}{|c|}{ Company } \\
\cline { 2 - 5 } & 1 & 2 & 3 & 4 \\
\hline$\Phi_{i}$ & $2 / 3$ & $2 / 3$ & $-2 / 3$ & $-2 / 3$ \\
\hline$\pi, \pi_{i}^{\prime}$ & 1 & 0 & $1 / 2$ & $1 / 2$ \\
\hline
\end{tabular}


Table 11. Distributions of power for a network shown in Fig. 3b

\begin{tabular}{|c|c|c|c|c|c|}
\hline \multirow{2}{*}{ Index } & \multicolumn{2}{|c|}{ Investor } & \multicolumn{3}{c|}{ Company } \\
\cline { 2 - 6 } & 1 & 5 & 2 & 3 & 4 \\
\hline$\Phi_{i}$ & $16 / 30$ & $41 / 30$ & $-19 / 30$ & $-19 / 30$ & $-19 / 30$ \\
\hline$\pi, \pi_{i}^{\prime}$ & $11 / 20$ & $9 / 20$ & $6 / 20$ & $7 / 20$ & $7 / 20$ \\
\hline
\end{tabular}

Comparing the powers assigned by the indices $\Phi, \pi$, and $\pi^{\prime}$ to firms 1 and 2 in Tables 10 and 11 , we can see that all three indices fail the link addition 1 and 2 properties.
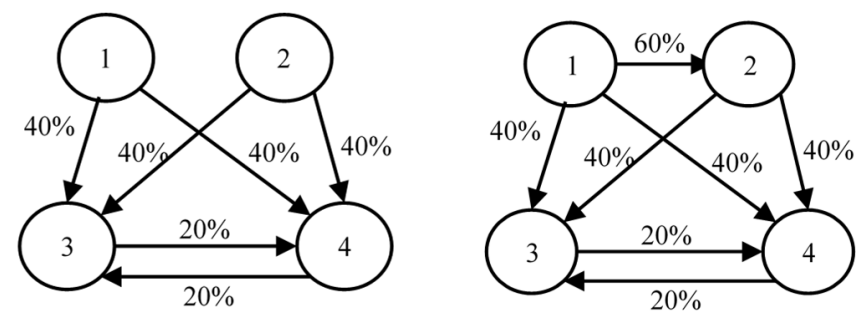

Fig. 4. Network composed of four firms: two companies and two investors (a) and the same network with one investor (firm 1) and three companies (firms 2-4) (b)

Example 4. Figure 4a shows a network composed of four firms: two companies and two investors. For this case, the $\Phi, \pi$, and $\pi^{\prime}$ indices are calculated in Table 12. Adding the linkage $(1,2)$ to the network in Fig. $4 \mathrm{a}$, we obtain the network with one investor (firm 1) and three companies (firms 2, 3, and 4) presented in Fig. 4b.

Table 12. Distributions of power for a network given in Fig. 4a

\begin{tabular}{|c|c|c|c|c|}
\hline \multirow{2}{*}{ Index } & \multicolumn{2}{|c|}{ Investor } & \multicolumn{2}{c|}{ Company } \\
\cline { 2 - 5 } & 1 & 2 & 3 & 4 \\
\hline$\Phi_{i}$ & $2 / 3$ & $2 / 3$ & $-2 / 3$ & $-2 / 3$ \\
\hline$\pi, \pi_{i}^{\prime}$ & $1 / 2$ & $1 / 2$ & $1 / 2$ & $1 / 2$ \\
\hline
\end{tabular}

For the network in Figure $4 \mathrm{~b}$, the $\Phi, \pi$, and $\pi^{\prime}$ indices are calculated in Table 13 .

Table 13. Distributions of power for a network given in Fig. $4 \mathrm{~b}$

\begin{tabular}{|c|c|c|c|c|}
\hline \multirow{2}{*}{ Index } & Investor & \multicolumn{3}{|c|}{ Company } \\
\cline { 2 - 5 } & 1 & 2 & 3 & 4 \\
\hline$\Phi_{i}$ & $13 / 6$ & $-1 / 2$ & $-5 / 6$ & $-5 / 6$ \\
\hline$\pi, \pi_{i}^{\prime}$ & 1 & $3 / 17$ & $7 / 17$ & $7 / 17$ \\
\hline
\end{tabular}


Comparing the values of the powers assigned to firms 1 and 2 by the $\Phi, \pi$, and $\pi^{\prime}$ indices in Tables 12 and 13, we see that both firms have a different gain or loss in power due to the addition of linkage $(1,2)$. Thus, the $\Phi, \pi$, and $\pi^{\prime}$ indices do not satisfy the link addition 3 property.

In our example (Fig. 3), we not only add a link (linkage $(5,2)$ ), but also a node (firm 5). Therefore, when we consider efficient power indices, it is obvious that the addition of a non-null player (firm) changes the distribution of power to satisfy the efficiency property. This means that the change in power can result not only from adding a linkage but (above all) as the consequence of one more non-null player and the efficiency of the power measure. Thus, it is our opinion that the three properties in this formulation (link additions 1,2, and 3) are not adequate for the standardised measures of control power in corporate shareholding structures. In fact, Peters et al. [38] consider these properties in the characterisation of a class of power indices (for invariant digraphs) based on four axioms: null player, constant sum, anonymity, and transfer properties.

\section{Concluding remarks}

The issue of measuring the indirect control power of the firms in complex corporate shareholding networks is of great interest to different researchers. In the literature on this topic, there are various approaches to measuring the power of the firms. Here, we were only interested in game theoretical approaches - particularly those that measure the power of all firms in whole corporate networks using power indices; i.e., the Karos and Peters [25], Mercik and Lobos [33], and modified Mercik and Lobos (Mercik and Stach, [34]) approaches. Indirect control in corporate shareholding networks is realised by directed linkages. The links reflect the relationships between firms in corporate networks. Two firms can be connected in a network in different ways, using direct or indirect links. From our point of view, it is interesting to have a method to measure the importance of mutual connections in corporate structures.

In this paper, we propose an approach to measure the importance (power) of the linkages (see Section 3). The method requires the adaptation of the existing methods to measure the power of all firms in corporate networks. Having the chosen method (thus, also having the distribution of power for all firms calculated by this method), we estimate the power of a linkage as the difference between the power of the firms where the linkages originate and the power of the same firm in a modified network (i.e., a network from which this connection was eliminated). In this way, we extend three indices $(\Phi, \pi$, and $\pi^{\prime}$ ) to measure the linkages' power.

Then, we continue the discussion started in [34] on the reasonable requirements for the indirect control measure of firms in corporate shareholding networks; in particular, we focus on the properties that refer to mutual connections (see Sect. 4). One further 
development may be the considerations on the desirable properties of the measures of linkages in corporate structures.

One idea for further development could be extensions of existing methods (the Karos-Peters or Mercik and Lobos, for example) to power indices with pre-coalitions, which would be important in a more thorough analysis of the control power of firms and their mutual connections.

Moreover, measuring the importance of linkages by a leaving-one-out approach without considering the interactions of a link with the different coalitions that can form the other links is not completely comprehensive. As a further development, a game theoretical approach following the ideas of the arc game and the position value for communication situations introduced by Meessen [31] and Borm et al. [9] could be interesting.

\section{Acknowledgements}

The research was financed by funds from AGH University of Science and Technology, and WSB University in Wrocław.

\section{References}

[1] Álvarez-Mozos M., Ferreira F., Alonso-Meijide J.M., Pinto A.A., Characterizations of power indices based on null player free winning coalitions, Optimization, 2015, 64 (3), 675-686, DOI: 10.1080/02331934.2012.756878.

[2] BANZHAF J.F., Weighted voting doesn't work: a mathematical analysis, Rutgers Law Rev., 1965, 19 (2), 317-343.

[3] Barua R., Chakravarty S.R., Roy S., On the Coleman indices of voting power, Eur. J. Oper. Res., 2006, 171 (1), 273-289, DOI: 10.1016/j.ejor.2004.07.064.

[4] Berle A., MeAns G., The modern corporation and private property, Commerce Clearing House, New York 1932.

[5] Bertini C., FreiXas J., Gambarelli G., Stach I., Comparing power indices, Int. Game Theory Rev., 2013, 15 (2), 1340004-1-1340004-19.

[6] Bertini C., MerciK J., Stach I., Indirect control and power, Oper. Res. Dec., 2016, 26 (2), 7-30, DOI: $10.5277 /$ ord 160202 .

[7] Bertini C., Stach I., Banzhaf voting power measure, [In:] K. Dowding (Ed.), Encyclopedia of Power, SAGE Publications, Los Angeles 2011, 54-55.

[8] Bertini C., StACH I., On public values and power indices, Dec. Making Manuf. Serv., 2015, 9 (1), 9-25, DOI: 10.7494/dmms.2015.9.1.9.

[9] Borm P., OWEN G., TIJS S., On the position value for communication situations, SIAM J. Discrete Math., 1992, 5, 305-320.

[10] Brams S.J., Game theory and politics, Free Press, New York 1975.

[11] CRAma Y., LeRUTH L., Control and voting power in corporate networks: concepts and computational aspects, Eur. J. Oper. Res., 2007, 178, 879-893, DOI: 10.1016/j.ejor.2006.02.020.

[12] Crama Y., Leruth L., Power indices and the measurement of control in corporate structures, Int. Game Theory Rev., 2013, 15 (3), 1-15, DOI: 10.1142/S0219198913400173. 
[13] Deegan J., Packel E.W., To the (minimal winning) victors go the (equally divided) spoils: a new power index for simple n-person games, [In:] S.J. Brams, W.F. Lucas, P.D. Straffin (Eds)., Political and related models. Modules in applied mathematics, Springer, New York 1983, DOI: /10.1007/978-1-46125430-0_10.

[14] DerKs J., Haller H., Null players out? Linear values for games with variable supports, Int. Game Theory Rev., 1999, 1, 301-314.

[15] Dubey P., Shapley L., Mathematical properties of the Banzhaf power index, Math. Oper. Res., 1979, $4(2), 99-131$.

[16] Felsenthal D., Machover M., Postulates and paradoxes of relative voting power. A critical reappraisal, Theory Dec., 1995, 38, 195-229.

[17] Felsenthal D.S., Machover M., The measurement of voting power. Theory and practice, problems and paradoxes, Edward Elgar Publishers, London 1998.

[18] Forlicz S., Mercik J., RAMSEy D., StaCh I., The Shapley value for multigraphs, [In:] N.T. Nguyen, E. Pimenidis, Z. Khan, B. Trawiński (Eds.), Comp. Coll. Int. LNAI, Vol. 11056, 10th International Conference, ICCCI 2018, Bristol, UK, September 5-7, 2018, Part II, 213-221, Springer, Cham 2018, DOI: 10.1007/978-3-319-98446-9 20.

[19] Freixas J., MarciniaK D., Pons M., On the ordinal equivalence of the Johnston, Banzhaf and Shapley power indices, Eur. J. Oper. Res., 2012, 216 (2), 367-375.

[20] Gambarelli G., Owen G., Indirect control of corporations, Int. J. Game Theory, 1994, 23, 287-302.

[21] Hu X., ShaPley L.S., On authority distributions in organizations: controls, Games Econ. Beh., 2003, $45,153-170$

[22] Hu X., Shapley L.S., On authority distributions in organizations: equilibrium, Games Econ. Beh., $2003,45,132-152$.

[23] Investopedia: https://www.investopedia.com/ask/answers/difference-between-preferred-stock-and- common -stock, accessed 11 February 2019.

[24] Johnston R.J., On the measurement of power. Some reactions to Laver, Environ. Plan. A, 1978, 10 (8), 907-914, DOI: 10.1068/a100907.

[25] Karos D., Peters H., Indirect control and power in mutual control structures, Games Econ. Beh., 2015, 92, 150-165, DOI: 10.1016/j.geb.2015.06.003.

[26] KILGOUR D.M., A Shapley value analysis for cooperative games with quarrelling, [In:] A. Rapoport (Ed.), Game theory as a theory of conflict resolution, D. Reidel, Dordrecht 1974, 193-206.

[27] KoŁodziej M., Stach I., Control sharing analysis and simulation, [In:] T. Sawik (Ed.), 13th International Conference on Industrial Logistics, ICIL 2016, Zakopane, Poland, AGH University of Science and Technology, Krakow 2016, 101-108.

[28] LaRuelle A., On the choice of a power index, Working Papers AD 1999-20, 1999, Instituto Valenciano de Investigaciones Económicas (Ivie).

[29] LEECH D., Shareholder voting power and ownership control of companies, Homo Oecon., 2002, 19, 345-371, DOI: 10.1007/978-3-642-35929-3_25.

[30] LEVy M., SZAFARZ A., Cross-ownership: a device for management entrenchment?, Review of Finance, 2017, 21 (4), 1675-1699, DOI: 10.1093/rof/rfw009.

[31] MeEssen R., Communication games, Master's thesis, Dept. of Mathematics, University of Nijmegen, The Netherlands, 1988 (In Dutch).

[32] Mercik J.W., A priori veto power of the president of Poland, Oper. Res. Dec., 2009, 19 (4), 61-75.

[33] MERCIK J., ŁOBOS K., Index of implicit power as a measure of reciprocal ownership, [In:] N.T. Nguyen, R. Kowalczyk, J. Mercik (Eds.), Transactions on Computational Collective Intelligence 23, Lecture Notes in Computer Science 9760, Springer, Heidelberg 2016, 128-140, DOI: 10.1007/978-3-662-52886-0_8. 
[34] Mercik J., Stach I., On measurement of control in corporate structures, [In:] N.T. Nguyen, R. Kowalczyk, J. Mercik, A. Motylska-Kuźma (Eds.), Transactions on Computational Collective Intelligence 31, Lecture Notes in Computer Science 11290, Springer, Berlin 2018, 64-79, DOI: 10.1007/978 -3-662-58464-4 7.

[35] Myerson R., Graphs and cooperation in games, Math. Oper. Res., 1977, 2 (3), 225-229.

[36] Nevison H., Structural power and satisfaction in simple games, [In:] S.J. Brams, A. Schotter, G. Schwödiauer (Eds.), Applied Game Theory, Physica, Heidelberg 1979, 39-57, DOI: 10.1007/9783-662-41501-6 3.

[37] Penrose L.S., The elementary statistics of majority voting, J. Royal Stat. Soc., 1946, 109 (1), 53-57, DOI: $10.2307 / 2981392$.

[38] Peters H., Timmer J., VAn Den Brink R., Power on digraphs, Oper. Res. Dec., 2016, 26 (2), 107-125, DOI: $10.5277 /$ ord 160207.

[39] Shapley L.S., SHUBIK M., A method for evaluating the distributions of power in a committee system, Am. Pol. Sci. Rev., 1954, 48 (3), 787-792, DOI: 10.2307/1951053.

[40] Stach I., Proper simple game, [In:] K. Dowding (Ed.), Encyclopedia of Power, SAGE Publications, Los Angeles 2011, 537-539.

[41] STACH I., 2011 Shapley-Shubik index, [In:] K. Dowding (Ed.), Encyclopedia of Power, SAGE Publications, Los Angeles 2011, 603-606.

[42] Sтасн I., Power measures and public goods, [In:] N.T. Nguyen, R. Kowalczyk, J. Mercik (Eds.), Transactions on Computational Collective Intelligence 23, Lecture Notes in Computer Science 9760 , Springer, Heidelberg 2016, 99-110, https://doi.org/10.1007/978-3-662-52886-0_6.

[43] STACH I., Indirect control of corporations: analysis and simulations, Dec. Making Manuf. Services, 2017, 11 (1-2), 31-51, DOI: 10.7494/dmms.2017.11.1-2.31.

[44] Straffin P.D., Power indices in politics, [In:] S.J. Brams, W.F. Lucas, P.D. Straffin (Eds.), Political and related models. Modules in applied mathematics, Springer, New York 1983, DOI: 10.1007/9781-4612-5430-0 11 .

[45] Turnovec F., Privatization, ownership structure and transparency: How to measure the true involvement of the state, Eur. J. Pol. Econ., 1999, 15, 605-618.

[46] VAN DEN BRINK R., The Apex power measure for directed networks, Soc. Choice Welf., 2002, 19 (4), 845-867, DOI: 10.1007/s003550200162.

[47] VAN DEN BRINK R., BORM P., Digraph competitions and cooperative games, Theory Dec., 2002, 53, $327-342$.

[48] VAN DEN BRINK R., GILles R., Measuring domination in directed networks, Soc. Net., 2000, 22, 141-157, DOI: $10.1016 / \mathrm{S} 0378-8733$ (00)00019-8. 